\title{
Methods for protecting network from islanding danger
}

\author{
Yasser Ahmed Elshrief*, Sameh Abd-Elhaleem**, Belal Ahmed Abozalam*** and A.D. Asham**** \\ *,****Electrical Department, Egyptian Academy for Engineering and Advanced Technology (EAE\&AT) affiliated to the Ministry of Military \\ Production, Egypt \\ **,*** Industrial Electronics and Control Engineering Department, Menofia University, Egypt \\ *Corresponding Author: yasserelshrief@eaeat.edu.eg
}

Submitted: $10 / 02 / 2020$

Revised: $\quad 09 / 12 / 2020$

Accepted: 20/12/2020

\begin{abstract}
The process of energizing loads from other sources like a distributed generator with a total disconnection of utility grid at the point of common coupling is called islanding. The islanding phenomenon affects the network by safety issues and bad impact on the utility and connected loads, especially the workers on the utility. Hence, it must be detected by a suitable anti-islanding (AI) technique which is needed to be faster in terms of time detection and smaller or negligible nondetection zone. To detect this phenomenon, there are local and remote AI techniques. In this paper, local AI techniques are illustrated, which are used for improving the performance regarding the size of the nondetection zone and detection speed.
\end{abstract}

Keywords: Anti-Islanding (AI); Distributed Generation (DG); Photovoltaic (PV); Power Quality; Utility GridConnected Photovoltaic; Islanding Detection.

\section{INTRODUCTION}

The claim for electricity over the world is growing, in addition to the numerous operational challenges of the traditional electric power system (EPS) and the huge cost of cables coming from long distances among the generation, transmission, and distribution stages till reaching prosumers. Besides, the traditional EPS is highly exposed to natural incidents as bad weather that leads to falling trees on power lines and makes a lot of faults. All these reasons increase the requirement of distributed generations (DGs) as an alternative solution of the traditional EPS (Y.A. Elshrief et al., 2019; A.G. Abo- Khalil., 2020). Figure 1 shows the difference between transferring power to prosumers through traditional EPS and DGs. The DGs are renewable sources such as solar, wind, and fuel cells which are a part of distributed energy resources. They include energy storage and responsive loads. The major driving forces behind the increased penetration of DGs are that they produce very small or no greenhouse gas emissions. They can reduce the transmission and distribution expansion along with the avoidance of large power plants. Also, they can reduce power losses and they are cost-effective to improve the power quality and reliability. Despite all of these advantages, DGs have a hazardous problem that affects the safety of the utility called islanding (M.F.N. Khan et al., 2020; C.a.K.H. Reddy et al., 2018; A.H. Mantawy et al., 2007; T. Zheng et al., 2018).

Islanding phenomenon, as shown in Figure 2, is a state in which a portion of the system containing one or more DG with local load remains energized while it is accidentally disconnected from the main utility system. An islanding condition can occur intentionally or unintentionally. The intentional islanding is performed due to the arranged maintenance required for the main utility, whereas the unintentional islanding may occur at any time due to regular faults or other uncertainties in the power system. When unintentional islanding happens, frequency and voltage in the islanded area cannot be controlled by the main utility system. It may produce a shock hazard for utility workers 
and lead to a damage to the network and prosumers equipment. Also, it has a bad impact on the protection, operation, and management of DGs. Because of all these explanations, unintentional islanding must be identified quickly and accurately.

There are two main techniques for detecting islanding, local and remote techniques, as shown in Figure 3. The remote techniques illustrated in Figure 4 need a huge infrastructure and a dependable communication system (Y.A. Elshrief et al., 2019 \& T. Zheng et al., 2018), requiring a high cost; thus, these techniques are hardly used on small scale.

This paper introduces in detail how to detect islanding based on local techniques and all the advantages and disadvantages of each technique especially the problem of the non-detection zone (NDZ) and their impact on the power quality.

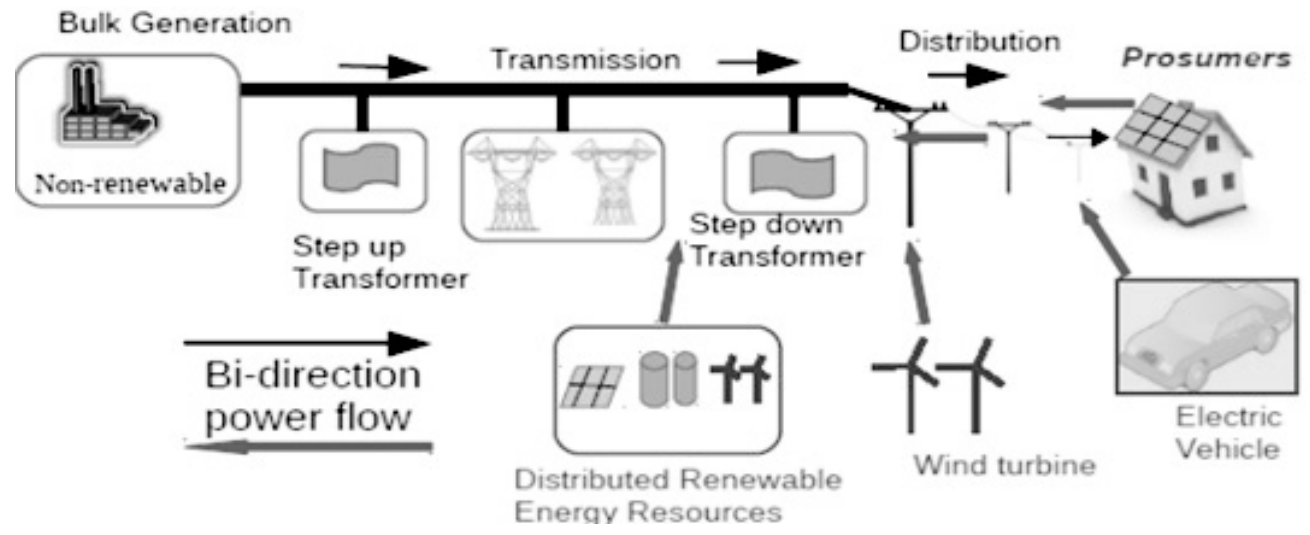

Figure 1. Power distribution system (traditional and modern).

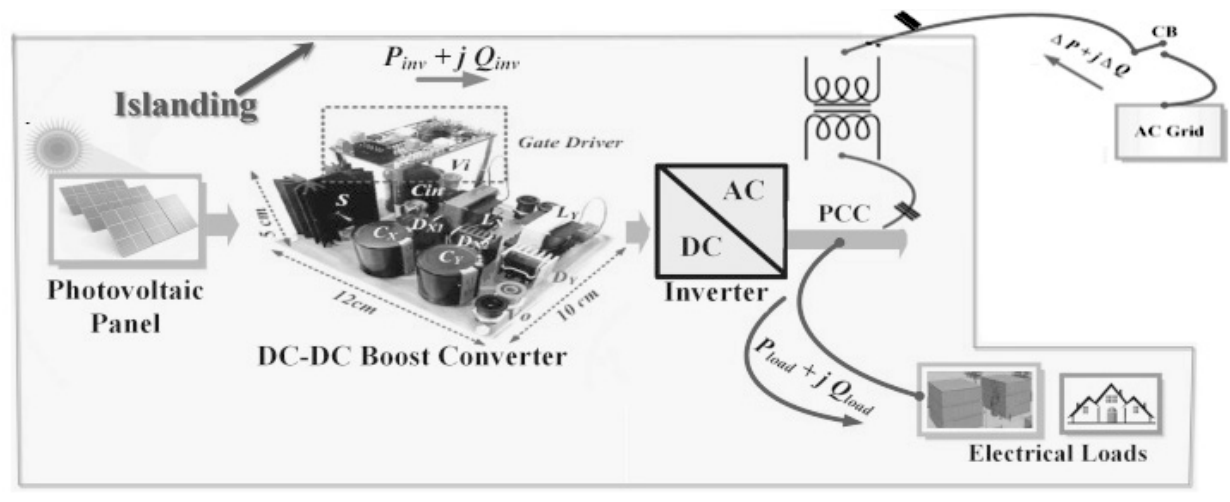

Figure 2. Islanding phenomenon.

NDZ, shown in Figure 5, is defined by the interval that the islanding phenomenon is failed to be detected by traditional anti-islanding (AI) techniques (W. Xu et al., 2004). In this case, both a reactive power variation $(\Delta \mathrm{Q})$ and a real power variation $(\Delta \mathrm{P})$ shown in Figure 6 are zero. Thus, the utility grid does not supply any power, and, consequently, the disconnection of utility could not be detected. So, NDZ can be considered as a main parameter for detecting islanding. 


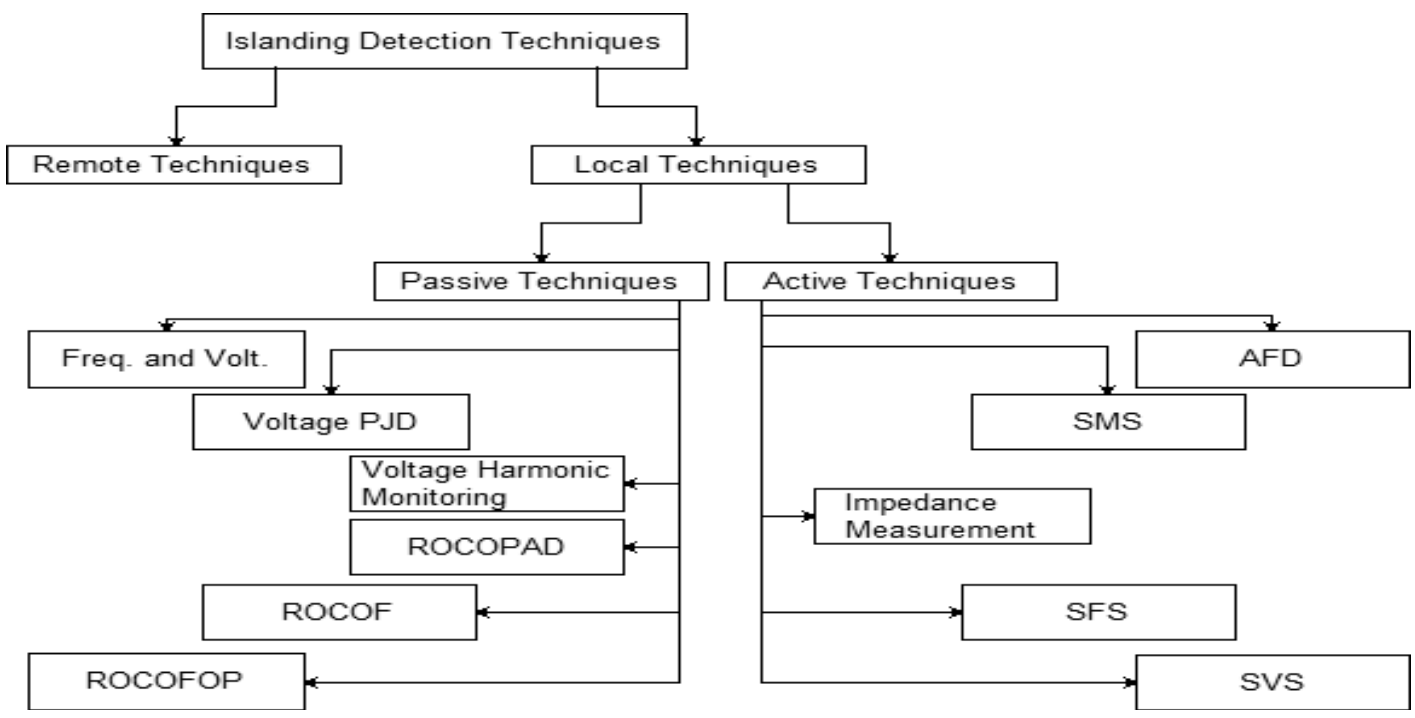

Figure 3. Types of AI detection techniques.
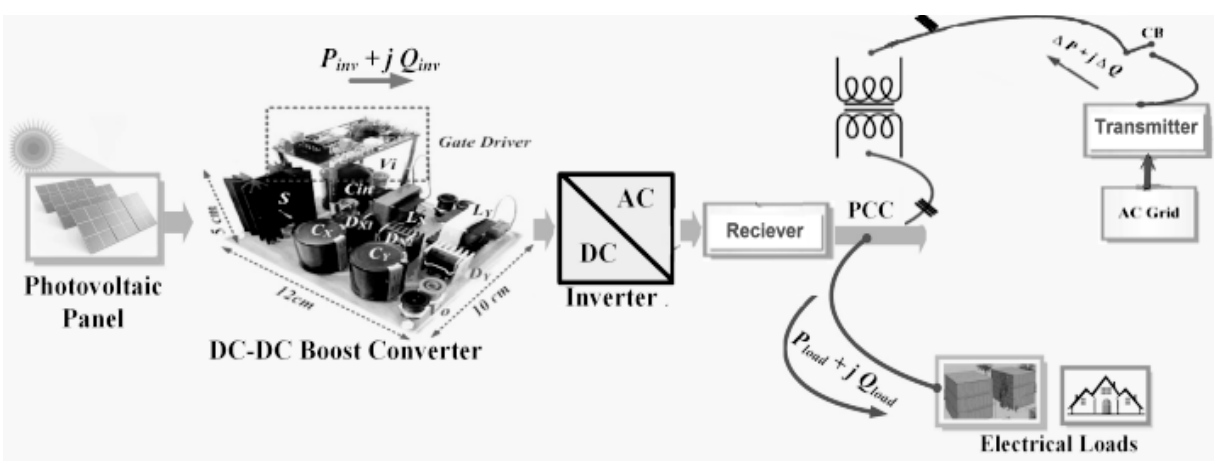

Figure 4. Transmitter and receiver in remote AI detection techniques.

The other aspect is the quality factor, which is illustrated in equation 1, for any known frequency known as the ratio of max stored energy over energy consumed per cycle times pi two (T. Zheng et al., 2018). The quality factor can be used to represent the relationship between stored energy and the dissipated one in RLC load, located between DG and utility grid as shown in Figure 6.

$$
\text { Quality factor }\left(Q_{f}\right)=2 * \frac{\text { Energy stored }}{\text { energy consumed per cycle }}
$$

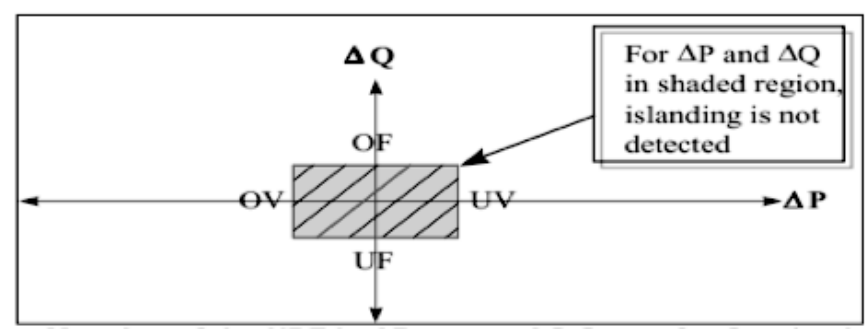

Figure 5. Non-detection zone (the non-detected area). 


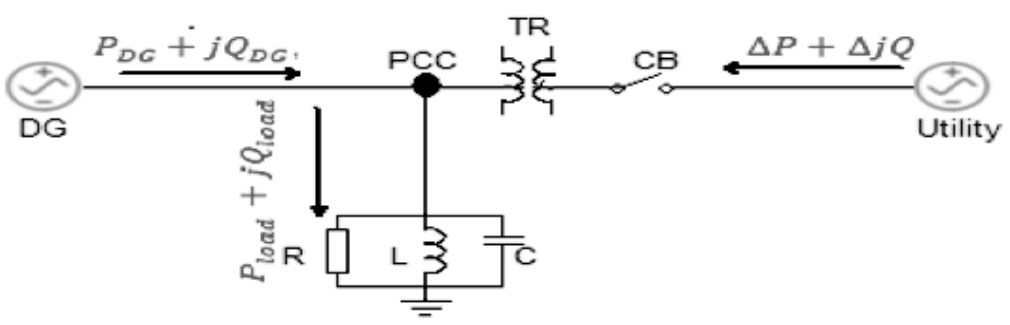

Figure 6. Power flow between the utility grid and distributed generation source.

\section{AI TECHNIQUES}

As shown in Figure 7, the operation of local AI techniques is presented in detail. Local AI techniques are divided into two classes, passive and active techniques. Each technique has some sub-techniques presented as follows.

\section{A. Passive Methods}

Passive methods rely on monitoring several parameters like frequency, current, voltage, and so on. Setting thresholds for these parameters can help in islanding detection if the value of any parameter is out of range. The implementation of these techniques is fast, easy, and uncomplicated and has no disturbance in the system. Despite all these advantages, they have a significant Non-Detection Zone that is considered the primary defect in these techniques (H. Abdi et al., 2020; B. Guha et al., 2015; M.A. Eltawil et al., 2010; B. Anudeep et al., 2017 \& H. Xu et al., 2020).

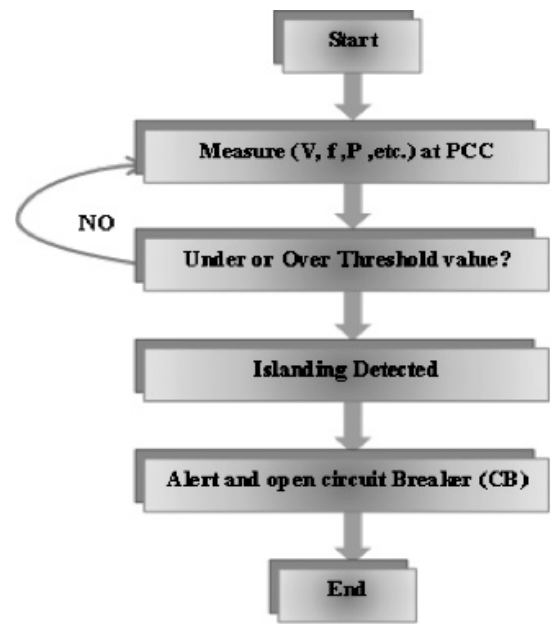

(a) Passive techniques

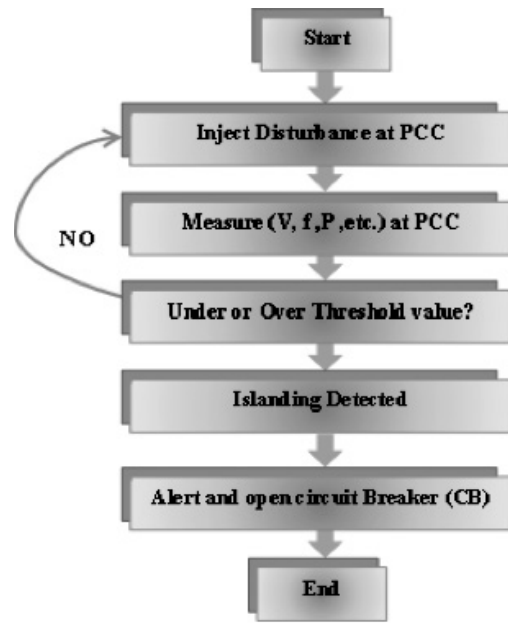

(b) Active techniques

Figure 7. Local AI Techniques: (a) passive and (b) active.

The challenge in these passive methods is how to select the convenient threshold (S.I. Jang et al., 2004) to make sure that islanding has happened or that there is another disturbance affecting the system. The mechanism of detecting islanding for passive techniques is shown in Figure 7 (b).

Generally, passive techniques used for detecting islanding are the following.

- Frequency and Voltage Protection Technique

In this technique, the under-over frequency (UOF) and voltage (UOV) protection relays are considered the default protection technique for standard Photovoltaic (PV) grid-connected mode. The grid frequency and voltage limits, according to the IEEE 1547 standard, are summarized in Table 1. These limits are used to ensure that the DGs must 
stop feeding power to the utility if a value of frequency or voltage at the point of common coupling (PCC) exceeds the predefined thresholds.

In addition to protection, these protection methods are also considered simpler and more convenient methods for detecting islanding.

Figure 6 shows the connection between DG source (solar energy in our case) and utility grid through PCC. So the measurement across this point of common coupling can detect whether it is an islanding case or not, using the relays of under/over frequency and voltage (T.a.J.M.V.J.E.C. Pedrino, 2009). Their threshold limits are determined by Equations $4 \& 5$. The real and reactive power $(\Delta \mathrm{P})$ and $(\Delta \mathrm{Q})$ are declared by Equations $2 \& 3$.

$$
\begin{aligned}
& \Delta \mathrm{P}=P_{D G}-P_{L O A D} \\
& \Delta \mathrm{Q}=\mathrm{Q}_{D G}-Q_{L O A D}
\end{aligned}
$$

$P_{D G}$ and $Q_{D G}$ are the DG source real and reactive power, respectively. Similarly, $P_{L O A D}$ and $Q_{L O A D}$ are loads of real and reactive power.

If the local load is closer in value to the PV generation source, then it would be more challenging to detect islanding, as it will lead to minimal changes in current and frequency values (A.S. Aljankawey et al.,2010). So, the protection relays are not capable of detecting islanding accurately, as this AI technique has a large NDZ, as shown in Figure 5.

$$
\begin{aligned}
& \left(\frac{V}{V_{\text {max }}}\right)^{2}-1 \leq \frac{\Delta P}{P} \leq\left(\frac{V}{V_{\min }}\right)^{2}-1 \\
& 1-\left(\frac{f}{f_{\min }}\right)^{2} \leq \frac{\Delta Q}{P} \leq 1-\left(\frac{f}{f_{\max }}\right)^{2}
\end{aligned}
$$

Then, using the IEEE 1547 series standard is shown in Table 1 to calculate the exact limits for threshold.

Table 1. Standard IEEE 1547 for AI Techniques.

\begin{tabular}{l|l}
\hline Parameters & Standard \\
\hline Range of Voltage & $88 \% \leq \mathrm{V} \leq 110 \%$ \\
\hline Range of Frequency & $49.5 \mathrm{HZ} \leq \mathrm{f} \leq 50.5 \mathrm{HZ}$ \\
\hline Maximum time for islanding detection & 2 seconds \\
\hline Total Harmonic Distortion (THD \%) & $\leq 5 \%$ \\
\hline
\end{tabular}

- Voltage Phase-Jump Detection (VPJD) Technique

The VPJD technique is the phase variance between the inverter output current and its terminal voltage (VPCC) in case of suddenly phase jump (A.S. Aljankawey et al., 2010) as shown in Figure 8. When transferring from normal operating mode to islanding one, the phase angle of VPCC will be shifted to look like the local load phase angle. This led to a sudden phase change in PCC. The VPJD technique can detect islanding by monitoring the rapid change in this phase angle. Typically, in PV inverter Phase Locked Loop (PLL) method can route the utility signal phase (M.S. Kim et al., 2019).

In current source inverters (CSI), synchronization between the inverter's output current and the utility grid voltage can be performed by detecting the fall or rise of VPCC zero crossing for the PCC during normal operation. Moreover, 
that may be occurred by using digital /analog PLL. In voltage source inverters (VSI), current and voltage are exchanged as in CSI case. Finally, having a unity power factor for grid-connected inverters is essential, as the non-detection zone of the phase-jump detection technique relies only on the power factor. During islanding, the power factor is based on the load. Changing the value of the power factor from unity may change the NDZ .Thus, the VPJD technique is also described as transient phase detection or power factor detection (M.H.a.N.R. Zamani, 2019; A. Llaria et al., 2011 \& W. Xu et al., 2007).

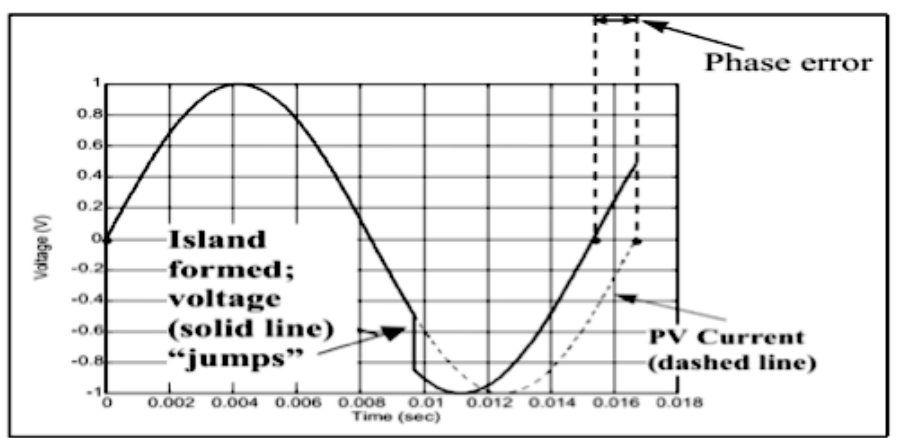

Figure 8. VPJD technique.

- Voltage Harmonic Monitoring Technique

The purpose of this technique is to follow the harmonic distortion of voltage to achieve the accurate detection of islanding. The basic operation mode is to control voltage at PCC, but, in islanding mode, PCC voltage and its harmonics can be controlled using DG (P. Mahat et al., 2008; P. Mahat et al., 2011 \& A. Khamis et al., 2013). It is considered that the whole harmonics distortion at PCC voltage, especially the standard harmonics like the 3rd, 5th, and 7 th, is provided using PLL.

- $\quad$ Rate of Change of Phase Angle Difference Technique (ROCOPAD)

In this technique, it starts with monitoring voltage, and current signals at the end of DG depend on the conditions of islanding and non-islanding. Phasor estimation is performed by the aid of phase, amplitude, and frequency. By using this information, phase angle difference is calculated and compared with ROCOPAD that is obtained, as shown in Equation 6 (A. Samui et al., 2011 \& W. Freitas et al., 2005).

$$
R O C O P A D=\frac{\Delta\left(\delta_{v}-\delta_{i}\right)}{\Delta t}
$$

$\delta_{i}$ and $\delta_{v}$ are current and voltage phase angles. This technique also has a fast response.

- $\quad$ Rate of Change of Frequency Technique (ROCOF)

ROCOF is used for detecting islanding using the time derivation of frequency. In the case of islanding, we will detect an extremely high value of ROCOF. (df/dt) shown in Equation 7 is used to estimate the islanding state. In this technique, islanding is detected based on the large mismatch in power. This technique becomes ineffective when DG's capacity becomes totally matched or nearly matched with its local loads (A. Samui et al., 2001; W. Freitas et al., 2005; E. O. Schweitzwer et al., 2010 \& Y.A. Elshrief et al., 2019).

$$
R O C O F, \frac{d f}{d t}=\frac{\Delta P}{2 H G} f
$$

$\Delta P$ is the power mismatch between loads and generation capacity at the Distribution Generation (PV) side, $\mathrm{G}$ is the rated generation capacity of DG/system, and $\mathrm{H}$ is the moment of inertia of DG/system. 
- $\quad$ Rate of change of frequency over power Technique (ROCOFOP)

Here, the detection of islanding can be done according to the concept of the ROCOF over the change of power (df/ $\mathrm{dp})$. This method of ( $\mathrm{df} / \mathrm{dp}$ ) will be more accurate than ( $\mathrm{df} / \mathrm{dt}$ ) especially in the case of power nearly matched between any DG source and local load (R. Nale et al., 2017 \& C.S. Chandrakar et al., 2012).

All of the mentioned techniques are related to the passive islanding detection techniques that have nearly the same characteristics. These techniques commonly collect some electrical parameters to improve the performance of detection. But, the requirement to calculate all these parameters at the same time will be cost-effective (J.a.A. Pandian., 2019; M. Ropp et al., 2006 \& B. Yu et al., 2009). Practically, all passive AI techniques do not affect the power quality of the system, but unfortunately, they have a large NDZ, so the other type of local islanding techniques will be illustrated.

\section{B. Active methods}

Active methods introduce intentional disturbances to the rest of the circuit and then analyze the feedback to decide whether there is an island or not. These methods have small NDZ, but unfortunately, it leads to a decrement of the systems' power quality, as they may change the magnitude of the inverter's output, either frequency or current.

Despite that there are some active methods that can detect islanding without decreasing power quality, it will require the use of many controllers that will increase the complexity of implementation and will be more expensive than the other local techniquess (P. Gupta et al., 2018; G. Hernandez-Gonzalez et al., 2006 \& F. Mango et al., 2006).

- $\quad$ Active Frequency Drift (AFD) Technique

Here, some disturbance of the current signal is injected into the PCC depending on $V_{P C C}$ (PCC voltage) following the fundamentals of $I_{i n v}$ (inverter current).

In the grid-connected mode, this distortion does not affect current and voltage and so the frequency of the system has the same frequency as the grid. In the grid-disconnected mode (islanding condition), the distortion leads to a phase difference between the current and voltage, and hence this difference leads to a drift in frequency that obligates the UF/ OF relays to cutoff the DG from the rest of the circuit. As shown in Figure 9, it is a comparison between a waveform of distorted DG output current and undistorted sine waveform. "Chopping factor" $C_{f}$ that is used to calculate the intensity of the disturbance is represented in Equation 8 and is defined as the ratio of the zero time $t_{z}$ to half of the period of the voltage waveform, $T / 2$.

$$
C_{f}=\frac{2 t_{z}}{T}
$$

As $T$ is the voltage period of the grid, $t_{z}$ is a dead time. However, this technique can be easily implemented using a microprocessor. It affects the power quality (H. Karimi et al., 2008; B. Wen et al., 2015; J.H. Kim et al., 2011; H. Li et al., 2018; N. Boonyapakdee et al., 2013; F. Liu et al., 2010, E.-R. Hatata., 2018; M.EL-Moubarak et al., 2015; L.P. Raghav et al., 2014; A. Yafaoui et al., 2010; W. Huang et al., 2013; \& Y.A. Elshrief et al., 2020).

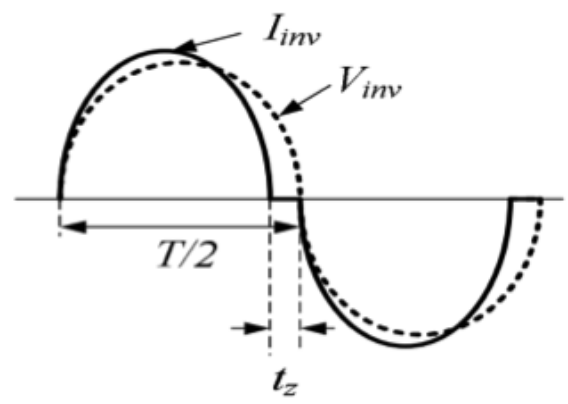

Figure 9. Waveform of AFD technique (E.-R. Hatata., 2018). 
- $\quad$ Slip-Mode Frequency Shift (SMS) Technique

In this Technique, SMS is based on a positive feedback destabilization for the output of the inverter to detect islanding state that changes in relation to the grid voltage.

In grid disconnection mode, it will obligate the frequency of the voltage at PCC to deviate from the standard value. In contrast to the other active methods, SMS is characterized by a limited NDZ and is assumed to be an efficient method for AI detection. In contrast with the other methods that depend on positive feedback, SMS has some drawbacks like perturbation in the phase shift that can cause noise, quantization error, and measurement error. By using an extra phase shift known as the improved slip-mode frequency (IM-SMS), we can overcome all drawbacks of SMS. Besides, it will be easier to implement, simpler, and more reliable (J. Merino et al., 2014).

- Impedance Measurement Technique

This technique is classified as a passive technique, as it monitors the variations of the system impedance that occurred by islanding. It will lead to a reduction in voltage and current due to temporarily parallel-connected inductors across the utility grid, but it nearly has no non-detection zone, especially in the single-inverter case (S. Dutta et al., 2018).

In grid-connected mode, in case of a large difference between the harmonic frequency impedance of the DG and the load, as shown in Figure 10, the equivalent impedance will be smaller due to the existence of low impedance $Z_{\text {Grid }}$ that is parallelly connected with $Z_{\text {Load }}$ as shown in Equation 9.

However, in the case of islanding mode, there is only one way to flow, so any difference can force the under/over voltage protection relays to work and stop the inverter's operation.

$$
Z_{\text {Equivelant }}=\left\{\begin{array}{cc}
Z_{\text {Load }} \| Z_{\text {Grid }} & \text { if grid connected } \\
Z_{\text {Load }} & \text { if islanding }
\end{array}\right.
$$

As these experimental studies prove that the method of impedance measurement used for detecting islanding may have small NDZ in the single-inverter cases, the main disadvantage appears in parallel multiple inverters cases, as each one forces a slightly different signal into the line (M. opp et al., 2006). Adding a variable length in phase shift will lead to an increase in the accuracy for the single-inverter case. But unfortunately, this enhancement will add a few numbers of harmonics to the output of the inverter. So, other active AI methods are used to solve the drawbacks of impedance measurement techniques.

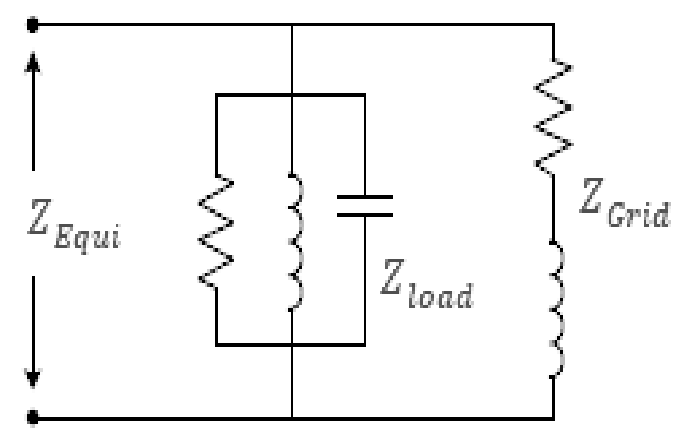

Mode of grid connection

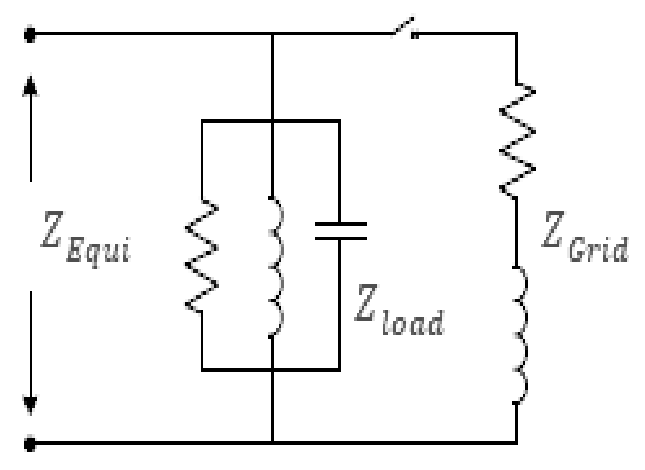

Mode of grid disconnection

Figure 10. Equivalent impedance within grid connection and disconnection mode. 
- $\quad$ Sandia Frequency Shift (SFS) Technique

In this technique, SFS is known as a modified active frequency drift (AFD) technique as it depends on feedback by injecting a small phase shift at the output current of the inverter. So, a deviation between the inverter output current and power system frequencies is found. Equation 10 shows the chopping factor that is proportionally related to the difference between the utility and inverter frequency.

$$
C_{f}=C_{f 0}+\mathrm{K}\left(f_{0}-\mathrm{f}\right)
$$

$C_{f 0}$ means chopping factor at zero frequency error, K means accelerating gain, and $f_{0}, f$ is the PCC measured frequency and line one, respectively. $C_{f}$ becomes low in case the error of frequency equals zero, as the utility stabilizes the voltage at PCC through a reference for phase and frequency.

In the case of grid connection mode, there is a small variation in frequency, but it has a negligible effect. However, in the case of islanding mode, when PCC frequency increases, then the frequency error increases, which in turn raises the frequency of the inverter. The process persists until it matched the limits of the threshold and islanding is detected. Although SFS has a reduced NDZ and is the most convenient among the other active methods, it reduces the output power quality of the inverter. Moreover, it introduces noise and harmonics (C.H. Yoo et al., 2011). So, detecting the islanding phenomenon has been done in this case by the under/over frequency protection relays taking action to stop the inverter's operation (C.H. Yoo et al., 2011; H.H. Zeineldin et al., 2011; H. Vahedi et al., 2012; X. Wang et al., 2011 \& A.G. Abo-Khalil et al., 2018).

\section{- Sandia Voltage Shift (SVS) Technique}

In this technique, the SVS is used for islanding prevention based on the method of positive feedback that mainly depends on the PCC's voltage amplitude. In the case of grid-connected mode, there is no effect on the power system, but when disconnection occurs between the utility grid and DG, it will lead to a reduction in PCC voltage. So, detecting the islanding phenomenon, in this case, can be done by using the under/over voltage protection relays and take action to stop the inverter's operation (C.L. Trujillo et al., 2010; B.I. Rani et al., 2013 \& A. Abo-Khalil., 2011). This technique has a smaller NDZ than the other techniques in addition to a fast detection speed if the convenient accelerating factor is chosen.

The recapitulation of the various local islanding detection methods and a comparison between passive and active techniques concerning its classification, concept, cost, the effect on power quality, size of NDZ, and cases in which detection of islanding will be failed has been shown in Table 2 . 
Table 2. A comparison of local islanding detection methods.

\begin{tabular}{|c|c|c|c|c|c|c|c|c|c|}
\hline & 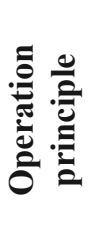 & 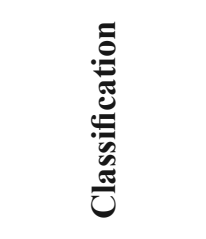 & 葛 & 全 & 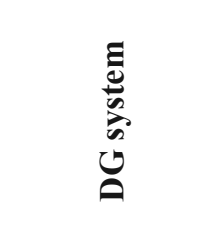 & 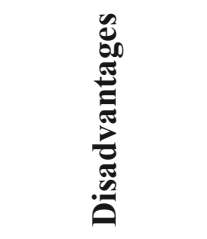 & 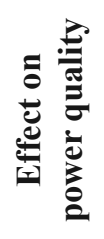 & $\overrightarrow{\tilde{n}}$ & : \\
\hline \multirow{6}{*}{ 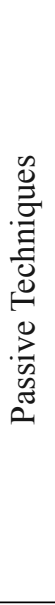 } & \multirow{6}{*}{ 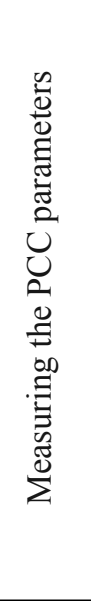 } & UOV & Voltage Variation & \multirow{6}{*}{ 总 } & Inverter based & NDZ & \multirow{6}{*}{ 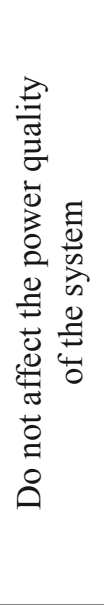 } & \multirow{6}{*}{ 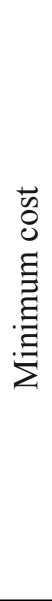 } & \multirow{6}{*}{ 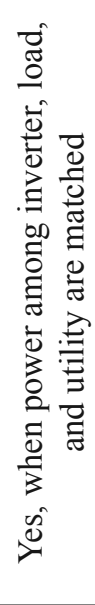 } \\
\hline & & UOF & Frequency Variation & & Inverter based & NDZ & & & \\
\hline & & $\begin{array}{c}\text { Voltage } \\
\text { Harmonic } \\
\text { Monitoring } \\
\end{array}$ & $\begin{array}{l}\text { Voltage phase } \\
\text { Difference }\end{array}$ & & Inverter based & Large NDZ & & & \\
\hline & & ROCOPAD & $\begin{array}{c}\text { phase angle for } \\
\text { voltage and current }\end{array}$ & & Not specified & Large NDZ & & & \\
\hline & & ROCOF & Frequency Variation & & Synchronous & NDZ & & & \\
\hline & & ROCOFOP & $\begin{array}{l}\text { variation of } \\
\text { active power and } \\
\text { frequency }\end{array}$ & & Not specified & NDZ & & & \\
\hline \multirow{5}{*}{ 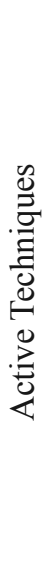 } & \multirow{5}{*}{ 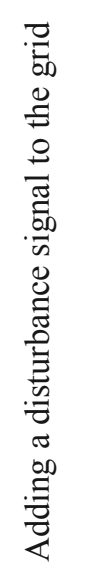 } & AFD & Frequency Variation & \multirow{5}{*}{$\begin{array}{l}\overline{\bar{\Xi}} \\
\text { ڤ }\end{array}$} & Inverter based & $\begin{array}{c}\text { fails for } \\
\text { high } Q_{\mathrm{f}} \text { loads }\end{array}$ & \multirow{5}{*}{ 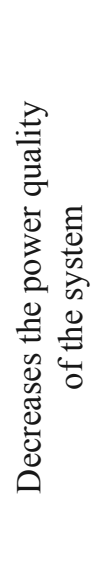 } & \multirow{5}{*}{ 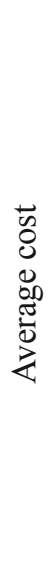 } & \multirow{5}{*}{ 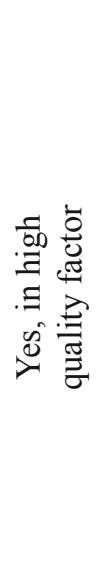 } \\
\hline & & SMS & $\begin{array}{c}\text { A variable } \\
\text { phase difference } \\
\text { between the } \\
\text { current and voltage }\end{array}$ & & VSC & $\begin{array}{l}\text { Current } \\
\text { distortion }\end{array}$ & & & \\
\hline & & $\begin{array}{l}\text { Impedance } \\
\text { Measurement }\end{array}$ & $\begin{array}{l}\text { Detect the variation } \\
\text { of utility impedance }\end{array}$ & & Synchronous & False tripping & & & \\
\hline & & SFS & $\begin{array}{c}\text { Zero-current } \\
\text { segment per half } \\
\text { cycle }\end{array}$ & & VSC & $\begin{array}{l}\text { Current } \\
\text { distortion }\end{array}$ & & & \\
\hline & & SVS & $\begin{array}{c}\text { Same as SFS } \\
\text { except for voltage }\end{array}$ & & Inverter based & $\begin{array}{l}\text { Voltage } \\
\text { distortion }\end{array}$ & & & \\
\hline
\end{tabular}

\section{CONCLUSION}

This paper demonstrated several updated local islanding detection techniques when connecting the utility grid to PV systems. Based on the whole discussion and trends at this point, local AI techniques are classified into passive and active. The passive techniques depend on displaying some parameters of the system as frequency and voltage. The other technique which is the active one mainly depends on injecting some perturbations on the output current or voltage of the inverter. According to the comparison, we can conclude that active methods can be characterized by small power degradations, faster response, and high reliability and can decrease NDZ. But these techniques are not as easy to implement as the passive ones. Passive techniques don't affect output power quality and are simple to be implemented, but they have large NDZ. So, it is recommended to use a hybrid technique that incorporates local techniques and artificial intelligence (Y.A. Elshrief et al., 2016; Y.A. Elshrief et al., 2016 \& Y.A. Elshrief et al., 2017) to have accurate islanding detection under various load conditions, which is predicted to be faster than all other methods and achieve the standard time according to IEEE 1547. 


\section{REFERENCES}

A.G. Abo-Khalil. 2020, Maximum Power Point Tracking for a PV System Using Tuned Support Vector Regression by Particle Swarm Optimization. Journal of Engineering Research, 8(4): 139-152.

A. Abokhalil, A. Awan, \& A.R. Al-Qawasmi. 2018, Comparative Study of Passive and Active Islanding Detection Methods for PV Grid-Connected Systems. Sustainability, 10(6): 1798.

A.G. Abo-Khalil. 2011, A new wind turbine simulator using a squirrel-cage motor for wind power generation systems. 2011 IEEE Ninth International Conference on Power Electronics and Drive Systems IEEE.

A.H. Mantawy, \& M. Al-Muhaini. 2007, A New particle-swarm-based algorithm for distribution system expansion planning including distributed generation. Proceedings of the 2nd IASME/WSEAS International Conference on Energy \& Environment, (EE’07). Portoroz, Slovenia.

A. Khamis, H. Shareef, E. Bizkevelci, \& T. Khatib. 2013, A review of islanding detection techniques for renewable distributed generation systems. Renewable and sustainable energy reviews, 28: 483-493.

A. Llaria, O. Curea, J. Jime'nez, \& H. Camblong. 2011, Survey on microgrids: unplanned islanding and related inverter control techniques. Renewable energy, 36(8): 2052-2061.

A.S. Aljankawey, W.G. Morsi, L. Chang, \& C.P. Diduch. 2010, Passive method-based islanding detection of renewable-based distributed generation: the issues. 2010 IEEE Electrical Power \& Energy Conference IEEE.

A. Samui, \& S.R. Samantaray. 2011, Assessment of ROCPAD relay for islanding detection in distributed generation. IEEE Transactions on Smart Grid, 2(2): 391-398.

A. Yafaoui, B. Wu, \& S. Kouro. 2010, Improved active frequency drift anti-islanding method with lower total harmonic distortion. IECON 2010-36th Annual Conference on IEEE Industrial Electronics Society IEEE.

B. Anudeep, \& P.k. Nayak. 2017, A passive islanding detection technique for distributed generations. 2017 7th International Conference on Power Systems (ICPS). IEEE. Sandia National Labs., Albuquerque, NM (US); Sandia National Labs.

B. Bahrani, H. Karimi, \& R. Iravani. 2009, Nondetection zone assessment of an active islanding detection method and its experimental evaluation. IEEE Transactions on Power Delivery, 26(2): 517-525.

B. Guha, R.J. Haddad, \& Y. Kalaani. 2015, A passive islanding detection approach for inverter-based distributed generation using rate of change of frequency analysis. Southeast Con 2015, IEEE.

B.I. Rani, M. Srikanth, G.S. Ilango, \& C. Nagamani. 2013, An active islanding detection technique for current controlled inverter. Renewable energy, 51: 189-196.

B. Wen, D. Boroyevich, R. Burgos, Z. Shen, \& P. Mattavelli. 2015, Impedance-based analysis of active frequency drift islanding detection for grid-tied inverter system. IEEE Transactions on industry applications, 52(1): 332-341.

B. Yu, M. Matsui, A.G. Abo-Khalil, \& G.Yu. 2009, A Correlation-Based Islanding Detection Method Using Current Disturbance for PV System. Proceedings of the International Conference on Electrical Machines and Systems ICEMS. Tokyo, Japan.

C.H. Yoo, D.H. Jang, S.K. Han, D.S. Oh, \& S.S. Hong. 2011, A new phase drift anti-islanding method for grid-connected inverter system. 8th International Conference on Power Electronics-ECCE Asia IEEE.

C.S. Chandrakar, B. Dewani, \& D. Chandrakar. 2012, An assessment of distributed generation islanding detection methods. International Journal of Advances in Engineering \& Technology, 5(1): 218-228.

E.O. Schweitzer, D. Whitehead, G. Zweigle, \& K.G. Ravikumar. 2010, Synchrophasor-based power system protection and control applications. 2010 63rd Annual Conference for Protective Relay Engineers IEEE.

E. Roland. 1984, Best, Phase-Locked Loops. In Theory Design, and Applications, 53-86.

F. Liu, Y. Kang, \& S. Duan. 2007, Analysis and optimization of active frequency drift islanding detection method. APEC 07Twenty-Second Annual IEEE Applied Power Electronics Conference and Exposition IEEE. USA.

F. Liu, Y. Kang, Y. Zhang, S. Duan, \& X. Lin. 2010, Improved SMS islanding detection method for grid-connected converters. IET renewable power generation, 4(1): 36-42.

G. Hernandez-Gonzalez, \& R. Iravani. 2006, Current injection for active islanding detection of electronically-interfaced 
distributed resources. IEEE Transactions on power delivery, 21(3): 1698-1705.

H. Abdi, A. Rostami \& N. Rezaei. 2020, A Novel Passive Islanding Detection Scheme for Synchronous-type DG using Load Angle and Mechanical Power Parameters. Electric Power Systems Research, 106-112

H.H. Zeineldin, \& S. Conti. 2011, Sandia frequency shift parameter selection for multi-inverter systems to eliminate non-detection zone. IET Renewable Power Generation, 5(2): 175-183.

H. Karimi, A.Yazdani, \& R. Iravani. 2008, Negative-sequence current injection for fast islanding detection of a distributed resource unit. IEEE Transactions on power electronics, 23(1): 298-307.

H. Li, Z. Li, Z. Guo, \& J. Lu. 2018, A Novel Unscheduled Islanding Detection Method for Microgrid. MATEC Web of Conferences (Vol. 160, p. 04001). EDP Sciences, 14, pp. 810-816.

H. Vahedi, \& M. Karrari. 2012, Adaptive fuzzy sandia frequency-shift method for islanding protection of inverter-based distributed generation. IEEE Transactions on Power Delivery, 28(1): 84-92.

H. Xu, Y. Zhang, Z. Li, R. Zhao \& J. Hu, 2020, Reactive Current Constraints and Coordinated Control of DFIG's RSC and GSC During Asymmetric Grid Condition. IEEE Access, 8: 184339-184349.

J.H. Kim, J.G. Kim, Y.H. Ji, Y.C. Jung, \& C.Y. Won. 2011, An islanding detection method for a grid-connected system based on the goertzel algorithm. IEEE Transactions on Power Electronics, 26(4): 1049-1055.

J. Merino, P. Mendoza-Araya, G. Venkataramanan, \& M. Baysal. 2014, Islanding detection in microgrids using harmonic signatures. IEEE Transactions on Power Delivery, 30(5): 2102-2109.

L.P. Raghav, \& T. Sandhya. 2014, An active frequency drift method for an islanding detection of grid connected micro turbine generation system. Int. J. Innovat. Res. Sci. Eng. Technol.-(ICETS'14), 3(1).

M.A. Eltawil, \& Z. Zhao. 2010, Grid-connected photovoltaic power systems: Technical and potential problems-A review. Renewable and sustainable energy reviews, 14(1): 112-129.

M. El-Moubarak, M. Hassan, \& A. Faza. 2015, Performance of three islanding detection methods for grid-tied multi-inverters. 2015 IEEE 15th International Conference on Environment and Electrical Engineering (EEEIC) IEEE.

M.F.N. Khan. 2020, A Novel Probabilistic Generation Model for Grid Connected PV Based Distributed Generation. Journal of Engineering Research, 8(1): 230-401.

M. Ropp, D. Larson, S. Meendering, D. McMahon, J. Ginn, J. Stevens, et al. 2006, Discussion of a power line carrier communications-based anti-islanding scheme using a commercial automatic meter reading system. 2006 IEEE 4th World Conference on Photovoltaic Energy Conference IEEE.

M.S. Kim, R. Haider, G.J. Cho, C.H. Kim, C.Y. Won, \& J.S. Chai. 2019, Comprehensive review of islanding detection methods for distributed generation systems. Energies, 12(5): 837-845.

M.Vatani, T. Amrall, \& I. Soltan. 2014, Comparative of Islanding Detection Passive methods for Distributed Generation Application. International Journal of innovation \& Scientific Research, 8(2): 234-241.

Mango, F., M. Liserre, \& A. Dell'Aquila. 2006, Overview of anti-islanding algorithms for pv systems. part ii: Activemethods. 2006 12th International Power Electronics and Motion Control Conference IEEE.

N. Boonyapakdee, T. Sapaklom, \& M. Konghirun. 2013, An implementation of improved combine active islanding detection method based on frequency and phase perturbations. 2013 International Conference on Electrical Machines and Systems (ICEMS) IEEE.

P. Du, Z. Ye, E.E. Aponte, J.K. Nelson, \& L. Fan. 2010, Positive-feedback-based active anti-islanding schemes for inverter-based distributed generators: basic principle, design guideline and performance analysis. IEEE transactions on power electronics, 25(12): 2941-2948.

P. Gupta, R.S. Bhatia, \& D.K. Jain. 2018, Active Islanding Detection Technique for Distributed Generation. INAE Letters, 3(4): 243-250.

P. Mahat, Z. Chen, \& B. Bak-Jensen. 2008, Review of islanding detection methods for distributed generation. 2008 third international conference on electric utility deregulation and restructuring and power technologies IEEE.

P. Mahat, Z. Chen, \& B. Bak-Jensen. 2011, Review on islanding operation of distribution system with distributed generation. 
2011 IEEE Power and Energy Society General Meeting IEEE.

R. Nale, \& M. Biswal. 2017, Comparative assessment of passive islanding detection techniques for microgrid. 2017 International Conference on Innovations in Information, Embedded and Communication Systems (ICIIECS).IEEE.

R. Nale, K. Venkatanagaraju, S. Biswal, M. Biswal, \& N. Kishor. 2018, Islanding detection in distributed generation system using intrinsic time decomposition. IET Generation, Transmission \& Distribution, 13(5): 626-633.

S. Dutta, P.K. Sadhu, M.J.B. Reddy, \& D.KMohanta. 2018, Shifting of research trends in islanding detection method-a comprehensive survey. Protection and Control of Modern Power Systems, 1(1): 322-330.

S.I. Jang, \& K.H. Kim. 2004, An islanding detection method for distributed generations using voltage unbalance and total harmonic distortion of current. IEEE transactions on power delivery, 19(2): 745-752.

T.Skocil, O.Gomis-Bellmunt, D.Montesinos-Miracle, S.Galceran-Arellano, \& J.Rull-Duran. 2009, Passive and active methods of islanding for PV systems. 2009 13th European Conference on Power Electronics and Applications IEEE, 1-10.

T. Zheng, H. Yang, R. Zhao, Y. Kang, \& V. Terzija. 2018, Design, evaluation and implementation of an islanding detection method for a micro-grid. Energies, 11(2): 323-330.

V.E. Santos, A.G. Martins, \& C.H. Antunes. 2006, A multi-objective model for sizing and placement of distributed generation. WSEAS Transactions on Power Systems, 1(7): 1267-1272.

W. Huang, T. Zheng, F. Yuan, Z. Wang, S. Xu, X. Wang, et al. 2013, Analysis of the NDZ formulation theory of active frequency shift islanding detection method for grid-connected PV system. 2013 IEEE PES Asia-Pacific Power and Energy Engineering Conference (APPEEC) IEEE.

W. Xu, G. Zhang, C. Li, W. Wang, G. Wang, \& J. Kliber. 2007, A power line signaling based technique for anti-islanding protection of distributed generators-Part I: Scheme and analysis. IEEE Transactions on Power Delivery, 22(3): 1758-1766.

W. Xu, K. Mauch, \& S. Martel. 2004, An assessment of distributed generation islanding detection methods and issues for Canada. CANMET Energy Technology Centre-Varennes, Natural Resources Canada, QC-Canada, Tech. Rep. CETC-Varennes.

X. Guo. 2016, Experimental verification of a new positive feedback islanding detection method for grid-connected inverter. Journal of Engineering Research, 4(3).

Y.A. Elshrief, S. Abd-Elhaleem, B.A. Abozalam, and A.D. Asham. 2021, Fast and Accurate Islanding Detection Technique for Microgrid Connected to Photovoltaic System. Journal of Radiation Research and Applied Sciences, to be published.

Y.A. Elshrief, A.D. Asham, D.H. Helmi, \& B.A. Abozalam. 2019, Merits and Demerits of the Distributed Generations Connected to the Utility Grid. Menoufia Journal of Electronic Engineering Research(ICEEM2019-Special Issue), 259-262.

Y.A. Elshrief, A.D. Asham, D.H. Helmi, \& B.A. Abozalam. 2019, On Remote Anti-Islanding Detection Techniques. THE FUTURE OF ELECTRICITY CHALLENGES AND OPPORTUNITIES, 297-304. https://cigre.moere.gov.eg/pages/publication.

Y.A. Elshrief, A.D.Asham, D.H.Helmi, \& B.A.Abozalam. 2019, ROCOF for detecting Islanding of Photovoltaic system. Menoufia Journal of Electronic Engineering Research (ICEEM2019-Special Issue), 255-258.

Y.A.Elshrief, G.A., Atlam, \& B.A. Abozalam. 2016, Adaptive-Fuzzy Logic Power Filter for Nonlinear Systems. IOSR Journal of Electrical and Electronics Engineering (IOSR-JEEE), 11(2): 66-73.

Y.A.Elshrief, G.A.,Atlam, \& B.A.Abozalam. 2017, Adaptive Hysteresis Active Power Filter using Fuzzy-Logic Controller for Nonlinear Systems. Menoufia Journal of Electronic Engineering Research, 26(1), 99-112.

Y.A. Elshrief, H.F. Elakbawy, G.A., Atlam, \& B.A. Abozalam. 2016, Comparison between the fixed_band HCC and adaptive HCC used for APF control. IOSR Journal of Electrical and Electronics Engineering (IOSR-JEEE), 11(3): 54-59.

Y.A. Elshrief, S. Abd-Elhaleem, A.D. Asham, \& B.A. Abozalam. 2020, AI protection Algorithms for PV-Grid Connection System. International Conference on Innovative Trends in Communication and Computer Engineering (ITCE), 334-341.

Y.A. Elshrief, S. Abd-Elhaleem, B.A. Abozalam, and A.D. Asham. 2021, A New Passive Islanding Detection Technique for Different Zones in Utility Grid . Journal of Engineering Research, to be published.

Y.A. Elshrief, S. Abd-Elhaleem, B.A. Abozalam, and A.D. Asham. 2021, On Active Anti-Islanding Techniques: Survey. Indonesian Journal of Electrical Engineering and Computer Science, 17(3): 1127-1134. 